\title{
Analyzing Gifted Students' Explanations for Daily Celestial Motion Based on the Earth-based and Heliocentric Frames of Reference
}

\author{
Donghyun Chae* · Jejun Han · Eunjeong Kim \\ Jeonju National University of Education
}

\begin{abstract}
This study aims to investigate gifted students' explanations for daily celestial motion from the Earthbased and heliocentric frames of reference. Eleven sixth-grade elementary school students were chosen for this study and data was collected through a questionnaire and an in-depth interview. The collected data was analyzed into celestial objects which are the Sun, the moon and the stars and analyzed based on the Earth-based and heliocentric perspectives again. As a result of the research, most gifted students were able to connect the Earth-based and heliocentric frames of reference with the Sun's daily apparent motion. However, they understood the daily apparent motion of the moon and the stars far less frequently compared to the Sun's motion and could not explain the Earth's rotation clearly. The result of the interview showed that the lack of understanding about the daily celestial motion was caused by inaccurate understanding of the Earth's rotation such as using memorized knowledge learned in school and guessing the answer.
\end{abstract}

Key words: Daily celestial motion, Frames of reference, The Earth's rotation

\section{I . Introduction}

National Science Education Standards (NRC, 1996) recommends that elementary school lower grade students understand the accurate patterns of the Sun, the moon and the stars' motion. The Atlas of Science Literacy(AAAS, 2001) requires that elementary school' s science education teach students to observe the daily apparent motions of the Sun, the moon and the stars and to explain those motions with the Earth's rotation. And Atlas suggests that learning astronomy begin with observing and describing daily patterns of motion of the Sun, the moon and the stars. Korean elementary science curriculum also recommends that students observe the daily celestial motions and explain that motions with the use of the Earth's rotation (The Ministry of Education and Human Resources Development, 2007). This is a complex reasoning area to understand and connect different frames of reference to observe celestial apparent motion from the Earth-based perspective and explain it from heliocentric perspective (Plummer et al.,
2011). To make this reasoning possible, students have to visualize the apparent motions of the celestial objects from their own Earth-based perspectives. And they must imagine the heliocentric frame of reference, which is from an observer outside the Earth, to explain why these objects appear the way that they do as seen from the Earth. This type of reasoning between moving frames of reference is necessary for other topics of astronomic phenomenon such as the phases of the moon and seasons (Plummer et al., 2011).

However the research found that students have trouble understanding celestial motions from the Earth-based perspective and heliocentric perspective. Sharp (1996) conducted an interview with 42 sixth grade British students which asked them to express their thinking about the position and the motion of the Sun, the moon and the stars in the sky in their language, sketches and gestures. As the result, $76 \%$ of students were able to give a general description of the Sun's rising and setting motion but less likely to do that of the moon

*Corresponding author: Donghyun Chae (donghyun@jnue.kr)

**Received on 7 March 2013, Accepted on 30 April 2013 
(36\%) and the stars (14\%). The difficulty of fully understanding the apparent motion occurred in teachers, too. Trumper (2006) found that only one of 20 Israeli secondary school teachers are capable of describing the Sun's motion scientifically. With the Earth-based frames of reference, it is also difficult to understand the celestial motion from heliocentric frames of reference. This is because to understand the heliocentric perspective they need to modify their own model and explain it logically as the observer could not observe directly from space (Subramaniam \& Padalkar, 2009).

Nussbaum (1986) pointed out that most explanations or reasonings in school's science class could not connect the celestial motion which was observed from Earth-based perspective and that from heliocentric perspective. Even many elementary school teachers rely on an artificial and synthetic models rather than a fully scientific model and some believe that teaching the Earth-based approach is wrong when they teach the motions of celestial objects (Shen \& Confrey, 2010). However the class based on explaining only heliocentric perspective did not allow students who observe things from the Earth to improve their knowledge and it could cause unscientific concepts of the celestial objects and the motions (Plummer, 2009). And understanding and learning the Sun and the moon's motion from the observer on the Earth is helpful to understand other important topics such as the phases of the moon and seasonal change to students (Kavanagh et al., 2005; Trundle et al., 2002, 2007).

Although understanding celestial motions from the Earth-based frames of reference and connecting those motions with them from heliocentric frames of reference is important, the related research is not accomplished yet (Plummer, 2009; Trumper, 2006). In a case of domestic research, the research to reveal misconceptions about astronomic concepts such as the Earth and the moon's motion (Byun et al.,
2004; Lee et al., 2011; Jung et al., 1995) and instructional reasearch for learning astronomic concepts (Na et al., 2010; Shim, 2004; Cho et al., 2011; Chae, 2004) are common. It is hard to find research of moving frames on specific celestial motions. This study has a purpose on recognizing how gifted students understand the Sun, the moon and the stars' motion which they can easily observe from the Earth-based perspective and how they connect that motion with heliocentric perspective.

For this study, we asked the following research questions.

1. How do gifted students recognize the daily apparent motion of the Sun?

2. How do gifted students recognize the daily apparent motion of the moon?

3. How do gifted students recognize the daily apparent motion of the stars?

\section{Research method}

\section{Participants}

For this study, 11 gifted students who are in the sixth grade of elementary school in small and medium-sized cities were selected randomly as participants. All students in this study passed selection tests of gifted students in a gifted education center of national university of education and they received high praise in science. For being chosen as gifted students in science, they had to pass three tests. First, they took a test for giftedness which consisted of several questions developed by Korean educational development institute. And the second test was to estimate student' s aptitude in science. The last test was an individual interview. This interview was conducted by a group of experts on science. The participants in this research consisted of 6 males and 5 females. All of them learned the Earth's rotation and daily celestial motion in the regular curriculum of an elementary school. 


\section{Data collection}

Eleven gifted students were asked to respond to a questionnaire to investigate gifted students' knowledge of daily celestial motion. In the questionnaire they had to draw the Sun, the moon and the stars' daily apparent motion and to write a reason for that motion (See Figure 1). An observer was located in the center of a hemisphere and the four cardinal points, north, south, east and west, were already printed in the drawing section of the questionnaire. And a transparent plastic hemisphere dome was introduced to help student's understand the questionnaire. The dome makes students know that the space shown in the questionnaire means third dimensional space in reality. At the top of the diagrams, the fact that the observer is looking south was written to make students describe directions of celestial motion. The gifted students were asked to describe the Sun's apparent motion during the day and the moon's and the stars' motion at night. The main questions were 'Draw how the Sun moves during the day.' , 'Draw how the moon moves at night.' and 'Draw how the stars move at night.'. These questions were made to allow students to draw daily celestial motion which they see from their own Earth-based perspectives. And the question 'Why do you think so?' was set right beside each drawing section. This question asked gifted students to write an explanation regarding their illustrations. All the gifted students had 30 minutes to complete the questionnaire.

After answering the questionnaire, an indepth interview was conducted with individual students. This interview took about 20 minutes per person and the questions in the interview were made up based on each student's questionnaire. Before the interview, researchers prepared each student's questionnaire, a transparent plastic hemisphere dome, a handheld globe and a light bulb(Figure 2). To investigate students' understanding of daily celestial motion, we asked why celestial objects appear the way that they drew them with each student's questionnaire. They were required to explain it in detail with the globe and the light bulb. Before they start to explain their answer, researcher told them that the light bulb is the Sun and the globe is our Earth. According their answer to the question, researcher asked different questions to them to figure out exactly how they understand the celestial motion. The interview was audio recorded and transcribed on the day of the interview.

\section{Data analysis}

Each aspect of daily celestial motion was broken down into categories describing aspects of the gifted students' descriptions and explanations. The collected data was classified how each student describes the Sun's, the moon'

* The person below is looking south. Answer the following questions.

\section{1-1. Draw how the Sun moves during a $1-2$. Why do you think so?} day.

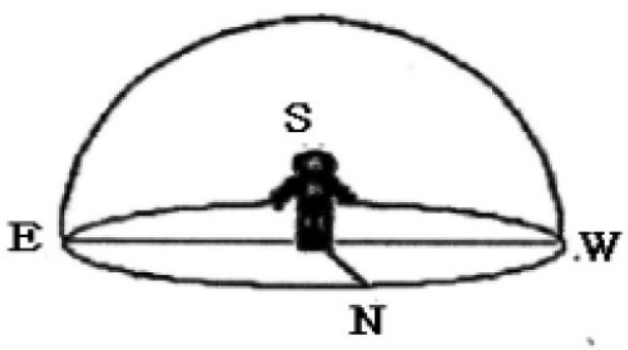

Figure 1. The questionnaire for asking the Sun's daily apparent motion. 


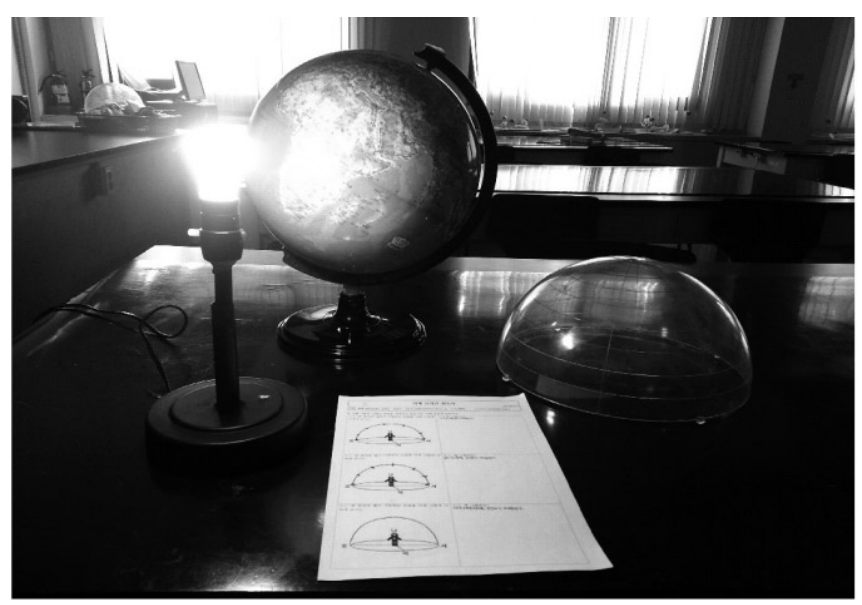

Figure 2. The interview situation.

$\mathrm{s}$ and the stars' pattern of apparent motion and explanation for that motion respectively(Table 1). First, the pattern of apparent daily celestial motion which they drew is analyzed. It was classified as a scientific one to draw celestial motion from the east to the south and to the west. And the case of drawing it from the east to the west was also regarded as a scientific one. Second, each gifted student's explanation for the motion was analyzed with the use of the questionnaire and the interview content together. An accurate explanation is to describe the Earth's rotation in the questionnaire and explain the apparent motion connecting the Earth's rotation with the celestial objects' rising and setting apparent motions through the use of a hand-held globe and a light bulb during the interview. On the other hand, it is considered as a non-scientific explanation if the gifted students use the Earth's rotation to explain celestial motion from the Earth-based perspective but could not explain it with using the globe and the light bulb scientifically. And the responses using the other reasons except for the Earth's rotation or non response was analyzed as an non-scientific one. In the case of the moon, the explanation of describing the moon's daily apparent motion with the use of the Earth's rotation was acceptable but mentioning that the moon does not actually move was regarded as a non-scientific one.

Table 1

Criteria of analysis

\begin{tabular}{|c|c|c|}
\hline The pattern of apparent motion & Explanation for the apparent daily motion & Criteria \\
\hline $\begin{array}{l}\text { - From the east to the south and the } \\
\text { west } \\
\text { - From the east to the west }\end{array}$ & $\begin{array}{l}\text { - Accurate use of the Earth's rotation with operating } \\
\text { a globe and a light bulb }\end{array}$ & Scientific \\
\hline $\begin{array}{l}\text { - From the east to the north and the } \\
\text { west } \\
\text { - From the east to the south, the } \\
\text { west and the north } \\
\text { - From the west to the south and the } \\
\text { east } \\
\text { - From the west to the north and the } \\
\text { east }\end{array}$ & $\begin{array}{l}\text { - Insufficient use of the Earth's rotation } \\
\text { - Use of the other factor such as the Earth's } \\
\text { revolution or the Moon's orbit } \\
\text { - Explanation for the Moon's motion that the Moon is } \\
\text { still with the Earth's rotation }\end{array}$ & $\begin{array}{c}\text { Non- } \\
\text { scientific }\end{array}$ \\
\hline
\end{tabular}




\section{Research result}

This section is to discuss the results of how scientifically sixth-grade gifted students in an elementary school know daily celestial motion. Through analyzing their drawings of apparent daily celestial motion and the interviews with them, we got the following results of their knowledge.

\section{The gifted students' awareness of the Sun's daily apparent motion}

Many students drew how the Sun appears to rise and set across the sky during a day exactly and explained the reason of why specifically and logically. Most gifted students (82\%) described the Sun's apparent daily motion from the east to the west. And all gifted students attempted to explain the Sun's apparent motion with something other than the Sun's actual motion. All but one of the gifted students used the Earth's rotation to explain the apparent motion of the Sun (92\%). Over the half of the gifted students (64\%) described the Sun's daily motion from the Earth-based perspective and explained how the Earth's rotation causes the Sun to appear to move. They explained that the Sun seems to move from the east to the west by the Earth rotating in the opposite direction, with turning a globe firsthand. Table 2 is an analyzed result of the gifted students' awareness of the Sun's daily motion.

Most gifted students explained the Sun's daily motion exactly with the globe and the bulb as seen in student F s following description(Figure 3) and interview.

\section{Table 2}

The gifted students' awareness of the Sun's daily apparent motion

\begin{tabular}{c|l|c|c|c}
\hline \hline $\begin{array}{c}\text { The pattern } \\
\text { of apparent } \\
\text { motion }\end{array}$ & \multicolumn{2}{|c|}{\begin{tabular}{c} 
Explanation for the apparent daily motion of the Sun \\
\multirow{3}{*}{ Scientific }
\end{tabular}} & $\begin{array}{c}\text { Gifted } \\
\text { student } \\
\text { ID }\end{array}$ & $\begin{array}{c}\text { The number of } \\
\text { gifted students } \\
\text { (n=11) }\end{array}$ \\
\cline { 2 - 5 } & $\begin{array}{l}\text { Insufficient explanations for the motion with the } \\
\text { use of the Earth's rotation }\end{array}$ & $\begin{array}{c}\text { Non- } \\
\text { scientific }\end{array}$ & H, I & $2(18 \%)$ \\
\hline \multirow{2}{*}{$\begin{array}{c}\text { Non- } \\
\text { scientific }\end{array}$} & $\begin{array}{l}\text { Insufficient explanations for the motion with the } \\
\text { use of the Earth's rotation }\end{array}$ & $\begin{array}{c}\text { Non- } \\
\text { scientific }\end{array}$ & G & $1(64 \%)$ \\
\cline { 2 - 5 } & $\begin{array}{l}\text { Insufficient explanations including the Earth } \\
\text { revolving around the Sun }\end{array}$ & $\begin{array}{c}\text { Non- } \\
\text { scientific }\end{array}$ & E & $1(9 \%)$ \\
\hline
\end{tabular}

1-1. Draw how the Sun moves during the day.

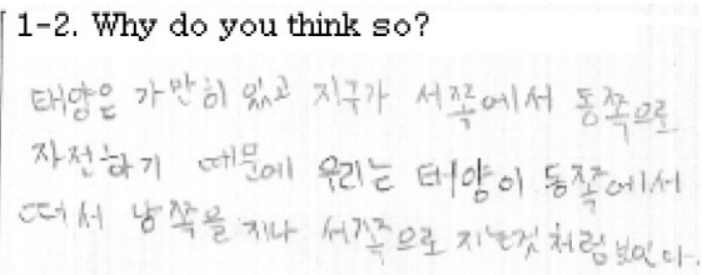

(Because the Sun doesa't move and the Earth rotates from the west to the east the Sun appears to rise in the east pass the south and set in the west)

Figure 3. Student F's description of the Sun's daily motion in the questionnaire. 
Student $F$ : If the Earth rotates from the west to the east, the Sun being still seems to rise in the east, pass the south and set in the west in Korea.(indicating Korea peninsula on the globe)The Sun lights on here.(turning the globe)the Sun appears to shine on the east and then, the south and set in the west.

On the other hand, there were students (18\%) who have a misconception during the interview explaining the daily motion even though they drew the Sun's daily motion accurately. One of these students was interviewed as follows.

\section{Researcher: Explain it (why the Sun moves the way you drew with this bulb and this globe).}

Student I: Um $\cdots$ Where is the east here? Is this the west? the east? If this is the east, does the Earth rotate like this?

Researcher: Where are you (in the globe)?

Student l: America.

This student has difficulty in explaining the motion even if describing the direction and the pattern of the Sun's daily motion correctly. Student I had a response that the Earth's rotation causes the Sun's daily motion but could not explain even how the Earth rotates.

There was a student who responded that the Sun seems to move from the east to the south and the west and then the north(Figure 4). This student described that the Earth's rotation is the cause of the Sun's daily motion. But the student also could not explain it explicitly. This student' $\mathrm{s}$ interview content is as follows.

Researcher:(Putting a globe and a light bulb on the desk) Then, explain your thought with these things here.

Student G: (turning the globe...) If we call this way the east and that way the west, it moves like this because the Earth rotates to the east. Researcher: Where are you (in the globe)? Student G: (indicating Korea peninsula) I am here.

Researcher: Then, how does it move to the east? You said, 'The Sun appears to move from the east to the west.' Right?

Student G: The Sun moves to the west $\cdots /$ sn't it right that the Sun rises in the east because people say 'Does the Sun rise in the west, today?' when we do something.

Student G justified the Sun's daily motion not by a scientific explanation but by a proverb. And this student confused the direction of the Earth' s rotation because of the lack of understanding directions when explaining the motion with the globe. This meant that the student answers to the question by using memorized conceptual knowledge. It was also analyzed that the scientific reasoning of the Sun's apparent motion is not formed in the student's cognitive
1- $\overline{1 .}$ Draw how the Sun moves during the day.

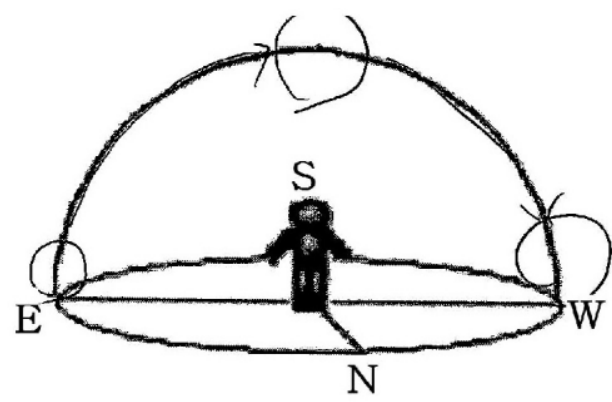

$1-2$. Why do you think so?

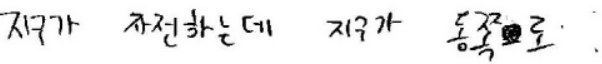

$\operatorname{ar} \frac{\pi(1-1)}{(0)}$ cerloglet

(It is because the Earth rotates to the east.)

Figure 4. Student G's description of the Sun's daily motion in the questionnaire. 
structure.

As seen in Figure 5, student E who explained the other cause except for the Earth's rotation described that the Earth's revolution causes the Sun to move from the west to the north and to the east. The student did not know how the Sun' s apparent motion is caused by the Earth's revolution and just mentioned it because of knowledge learned in school. Student E's interview and description are as below.

Researcher:(Does the Sun move )from the west to the east? What is the reason?

Student E: The reason why? I don't know that. I'm not sure what I learned in fifth grade, but I just wrote what I remember.

As a result of analyzing data of the Sun's motion, more than half of the gifted students (64\%) were able to move between the Earth based and heliocentric frames of reference. Based on it, it was shown that they could make the full connection between the Earth's rotation and the Sun's apparent daily motion. They had an ability to explain the fact that the Sun appears to rise and set across the sky because of our actual motion on the spinning Earth not the Sun's actual motion with the use of the globe and the light bulb. However the other gifted students described and explained the apparent daily motion of the Sun inaccurately and vaguely with an idea from a proverb or memorized knowledge learned in school.

\section{The gifted students' awareness of the moon's daily apparent motion}

Gifted students had difficulty in describing and explaining the apparent daily motion of the moon because they were less likely to know about the moon rather than the Sun. The following table 3 is about the analyzed results of the gifted students' awareness of the moon's apparent daily motion.

$73 \%$ of the gifted students had responses that the moon appears to rise in the east and to set in the west. The majority of the gifted students (82\%) used the Earth's rotation to explain the apparent daily motion of the moon. However, only two students among them (18\%) were capable of drawing a correct pattern of apparent motion and making an accurate connection between it and the explanation using the Earth's rotation with the use of the globe. A few students (36\%) attempted to explain the moon's apparent motion with the fact that the Earth rotates, but they did not make it. Also there was a student who explained the motion exactly with the Earth's rotation but does not believe the moon actually moves. 18\% gave responses that the moon's apparent daily motion was mainly caused by the moon's orbit even though

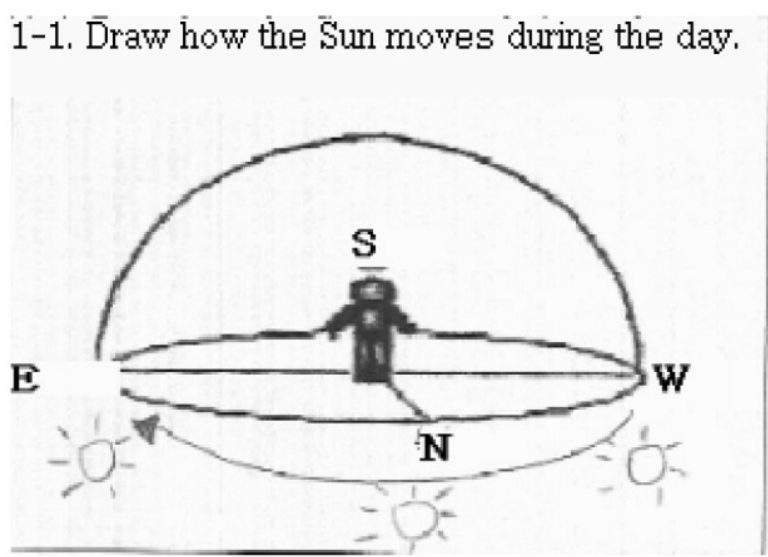

1-2. Why do you think so?

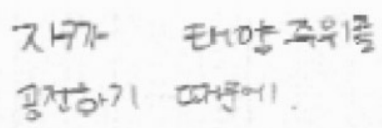

(It is because the Earth revolves around the Sun.)

Figure 5. Student E's description of the Sun's daily motion in the questionnaire. 


\section{Table 3}

The gifted students' awareness of the moon's daily apparent motion

\begin{tabular}{|c|c|c|c|c|}
\hline \multirow{2}{*}{$\begin{array}{l}\text { The pattern } \\
\text { of apparent } \\
\text { motion }\end{array}$} & \multicolumn{2}{|c|}{ Explanation for the apparent daily motion of the Moon } & \multirow{2}{*}{$\begin{array}{l}\text { Gifted } \\
\text { student } \\
\text { ID } \\
\text { J, F }\end{array}$} & \multirow{2}{*}{$\begin{array}{c}\begin{array}{c}\text { The number of } \\
\text { gifted students } \\
(\mathrm{n}=11)\end{array} \\
2(18 \%) \\
\end{array}$} \\
\hline & Accurate use of the Earth's rotation & Scientific & & \\
\hline Scientific & $\begin{array}{l}\text { Insufficient explanations for the motion with the } \\
\text { use of the Earth's rotation }\end{array}$ & $\begin{array}{l}\text { Non- } \\
\text { scientific }\end{array}$ & $\mathrm{B}, \mathrm{I}$ & $2(18 \%)$ \\
\hline \multirow{4}{*}{$\begin{array}{l}\text { Non- } \\
\text { scientific }\end{array}$} & $\begin{array}{l}\text { Insufficient explanations for the motion with the } \\
\text { use of the Earth s rotation }\end{array}$ & $\begin{array}{l}\text { Non- } \\
\text { scientific }\end{array}$ & $\mathrm{E}, \mathrm{G}$ & $2(18 \%)$ \\
\hline & $\begin{array}{l}\text { Accurate use of the Earth's rotation ; The moon } \\
\text { does not orbit. }\end{array}$ & $\begin{array}{c}\text { Non- } \\
\text { scientific }\end{array}$ & $\mathrm{D}$ & $1(9 \%)$ \\
\hline & $\begin{array}{l}\text { Explanations including the moon's orbit and the } \\
\text { Earth's rotation ; The moon's revolution is the } \\
\text { main cause. }\end{array}$ & $\begin{array}{l}\text { Non- } \\
\text { scientific }\end{array}$ & $\mathrm{C}, \mathrm{K}$ & $2(18 \%)$ \\
\hline & $\begin{array}{l}\text { Insufficient explanations including the Earth's } \\
\text { revolution }\end{array}$ & $\begin{array}{l}\text { Non- } \\
\text { scientific }\end{array}$ & A & $1(9 \%)$ \\
\hline $\begin{array}{l}\text { Non- } \\
\text { response }\end{array}$ & Cannot explain the moon's daily apparent motion & $\begin{array}{l}\text { Non- } \\
\text { scientific }\end{array}$ & $\mathrm{H}$ & $1(9 \%)$ \\
\hline
\end{tabular}

mentioning both the Earth's rotation and the moon's revolution during the interview.

The students who explained insufficiently the motion with the Earth's rotation was divided into two groups. One is the students who drew an accurate picture of the moon's apparent daily motion and the other is the students who drew non-scientific pattern of apparent motion. Student B in the former group drew this(Figure 6) and responded to the interview questions below.

2-1. Draw how the moon moves at night.

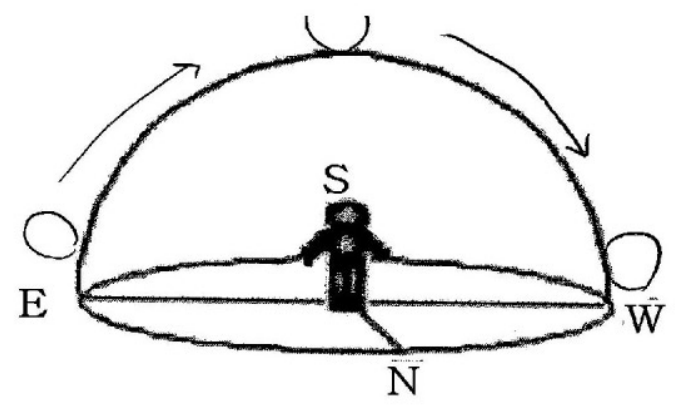

Researcher: Then, what does "the moon moves) from the east to the west" mean? Do you understand the meaning? Did you just memorize it?

Student B: I guessed so rather than memorizing it. I don't know well.

Researcher: Ok, then do you think the motion was observed from the Earth or from the space?

Student B: It was observed from the Earth.

Student B explained that the moon appears to

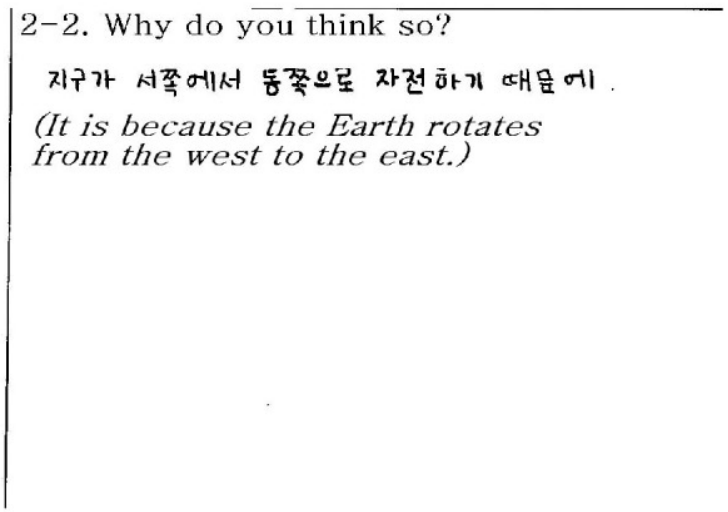

Figure 6. Student B's description of the moon's daily motion in the questionnaire. 
rise in the east and set in the west but answered "I guess so." to the question of why with avoiding a detailed explanation. This student recognized that the moon's apparent motion is observed from the Earth-based perspective but could not explain that motion scientifically.

The followings are a student's drawing (Figure 7) and the interview in the latter group, which gave non-scientific description of the pattern and explained the moon's apparent motion insufficiently with the use of the Earth's rotation.

Researcher: How about the moon's motion at night? Does the moon move from the west to the east like you said about the Sun?

Student E: No. It moves from the east to west. Researcher: Which direction does the moon move from the east to? You drew the pattern of the motion as it moves from the east to the north and then to the west. Why?

Student E: I don't know.

Student E described the moon's motion as seen above and was not able to explain the drawing. This revealed that the student drew the pattern of the moon's apparent motion based on not a scientific evidence but a guess.

One student explained that the moon's motion is due to the Earth's rotation well but believed that the moon stays. Some part of student D's interview content is as below.

Researcher: (In the process of explaining for the reason of the daily celestial motion) How about the moon's motion?

Student D: It occurs because the Earth rotates when the moon does not move.

Some students who use both the Earth's rotation and the moon's orbit to explain the motion accounted for $18 \%$ of all the gifted students. All of them gave non-scientific explanation that the moon's daily motion caused by the moon's orbit rather than the Earth's rotation. These student's interviews are as follows.

Student C: The moon's phase changes because the moon orbits around the Earth and the moon moves from the east to the west, the Earth rotating.

Researcher: Please explain more about "because the moon orbits around the Earth". How does the moon revolve around the Earth? Student $C$ : It means that the moon appears to move from the east to the west with our eyes as the moon orbits the Earth by gravity.

Student K: The moon $\cdots$. Even if the Earth rotates itself, the moon revolves around the Earth. So it appears to rise in the east and set

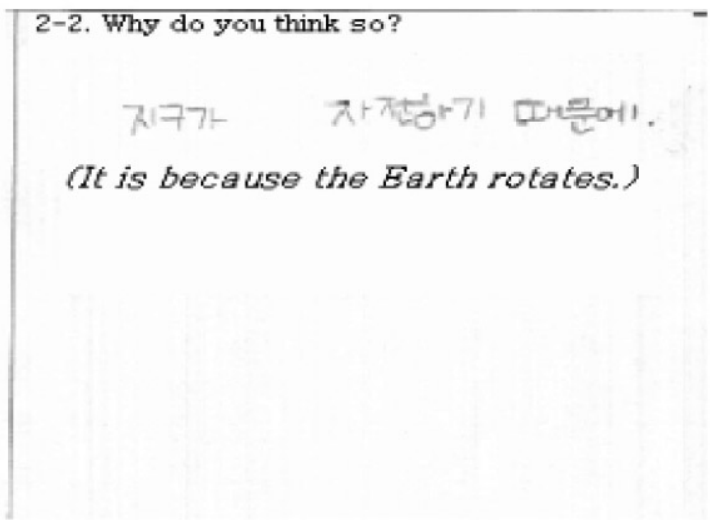

\section{2-1. Draw how the moon moves at night.}

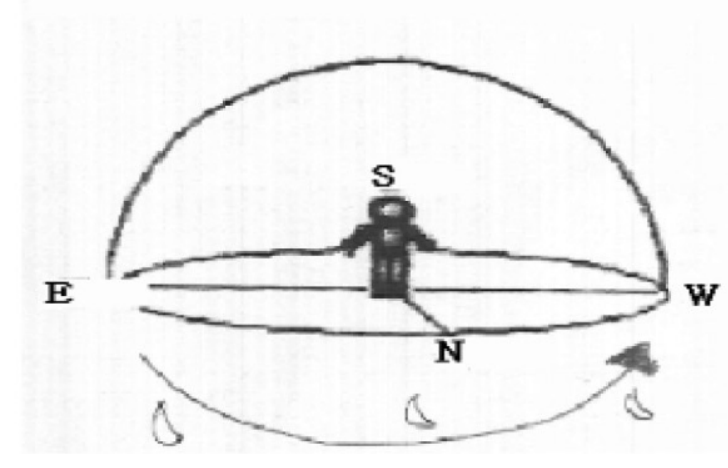

Figure 7. Student E's description of the moon's daily motion in the questionnaire. 
in the west.

Researcher: What caused this?

Student $K$ : It's because the moon revolves around the Earth.

As a result of analyzing these interviews, it was shown that they all misunderstood the moon's motion as the moon's orbit causes the apparent motion of the moon.

The next description (Figure 8) and interview were the one with the student who responded that the moon's daily apparent motion was caused by the Earth's rotation.

Researcher: Why (does the moon's daily apparent motion occur)?

Student A: It's because the Earth revolves..? Researcher: The Earth's revolution? How does the Earth revolve?

Student $A$ : The Earth revolves from the east to the west.

Student A used the Earth's revolution not the moon's actual motion to explain the moon's apparent motion. And it indicates the student is able to understand the moon's motion from the Earth-based frames of reference. However the student described the pattern of the moon's daily apparent motion as moving from the west to the east and explained that it was caused by the fact that the Earth revolves from the east to the west. It revealed that the accurate concept of the moon's motion and the Earth's revolution

\section{2-1. Draw how the moon moves at night.}

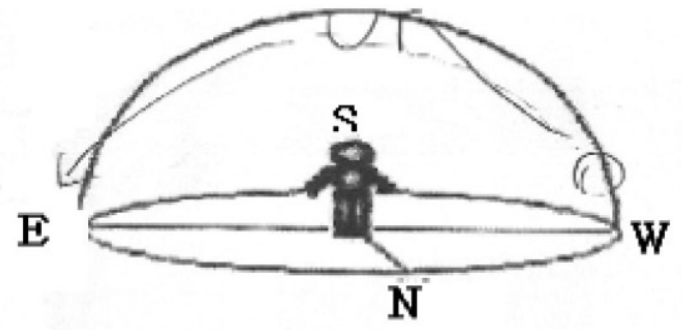

are not formed for this student. This student also thought that the moon' s daily motion for 24 hours and the moon's orbit were connected but could not make the full connection between them during the interview.

Other than those students, a student had a response that the moon moves from the east to the west like the Sun during the interview but did not know the reason.

As a result of analyzing gifted students' awareness of the Moon's daily apparent motion, the ratio of the students who used the Earth's rotation to explain the daily apparent motion of the Moon was high, but only few students were able to explain it in a scientific level. Only $18 \%$ of the gifted students thought that the moon orbits. All of those students explained that the moon's orbit causes the moon's daily apparent motion. Few gifted students knew the moon's daily apparent motion accurately and the rest of gifted students gave non-scientific descriptions and explanations such as the Earth's rotation or the moon's revolution as the cause of that motion.

\section{The gifted students' awareness of the stars' daily apparent motion}

$64 \%$ of the gifted students drew an accurate pattern of apparent daily motion of the stars. And the ratio of the gifted students who attempted to use the Earth's rotation to explain the apparent motion of the stars was as high as $82 \%$. However only 3 students (27\%) succeeded in

\section{2-2. Why do you think so?

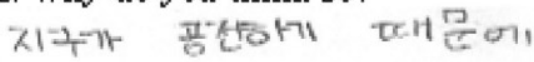

\section{(It is because the Earth revolves.)}

Figure 8. Student A's description of the moon's daily motion in the questionnaire. 
making an accurate connection between the apparent motion of the stars and the Earth's rotation. The result of analyzing the gifted students' awareness of the stars' daily apparent motion is as below (Table 4).

Among the gifted students, student $J$ was one of the students who described and explained the stars' daily apparent motion accurately with the use of the Earth's rotation. The student's drawing (Figure 9) and interview are as follows.

Researcher: (Setting the light bulb and the globe on the desk) This is the bulb, which is the Sun, the moon and the stars. Explain the stars' daily motion with these things.

Student J: (turning the globe) The Earth spins like this when it moves from the west to the east. Right? The bulb lights on America and the light moves this way because the Earth spins. So the stars appear to move across the sky from the east to the west when we see in Korea.

Also, some students (18\%) described the pattern of the stars' daily apparent motion accurately and wrote down the Earth's rotation as the cause of that motion in the questionnaire but had insufficient explanation, making their

\section{Table 4}

The gifted students' awareness of the stars' daily apparent motion

\begin{tabular}{|c|c|c|c|c|}
\hline $\begin{array}{l}\text { The pattern } \\
\text { of apparent }\end{array}$ & \multicolumn{2}{|c|}{ Explanation for the apparent daily motion of the stars } & $\begin{array}{l}\text { Gifted } \\
\text { student }\end{array}$ & $\begin{array}{l}\text { The number of } \\
\text { gifted students }\end{array}$ \\
\hline \multirow{3}{*}{ Scientific } & Accurate use of the Earth's rotation & Scientific & $\mathrm{D}, \mathrm{F}, \mathrm{J}$ & $3(27 \%)$ \\
\hline & $\begin{array}{l}\text { Insufficient explanations for the motion with the } \\
\text { use of the Earth's rotation }\end{array}$ & $\begin{array}{l}\text { Non- } \\
\text { scientific }\end{array}$ & $\mathrm{B}, \mathrm{I}$ & $2(18 \%)$ \\
\hline & $\begin{array}{l}\text { Insufficient explanations for the motion with the use } \\
\text { of the Earth's rotation and the Earth's revolution }\end{array}$ & $\begin{array}{l}\text { Non- } \\
\text { scientific }\end{array}$ & $\mathrm{K}$ & $1(9 \%)$ \\
\hline $\begin{array}{l}\text { Non- } \\
\text { scientific }\end{array}$ & $\begin{array}{l}\text { Insufficient explanations for the motion with the } \\
\text { use of the Earth's rotation }\end{array}$ & $\begin{array}{l}\text { Non- } \\
\text { scientific }\end{array}$ & $\mathrm{A}, \mathrm{E}, \mathrm{G}$ & $3(27 \%)$ \\
\hline \multirow{2}{*}{$\begin{array}{l}\text { Non- } \\
\text { response }\end{array}$} & $\begin{array}{l}\text { Insufficient explanations including the Earth's } \\
\text { revolution }\end{array}$ & $\begin{array}{l}\text { Non- } \\
\text { scientific }\end{array}$ & $\mathrm{C}$ & $1(9 \%)$ \\
\hline & Cannot explain the moon's daily apparent motion & $\begin{array}{l}\text { Non- } \\
\text { scientific }\end{array}$ & $\mathrm{H}$ & $1(9 \%)$ \\
\hline
\end{tabular}

3-1. Draw how the stars move at night.

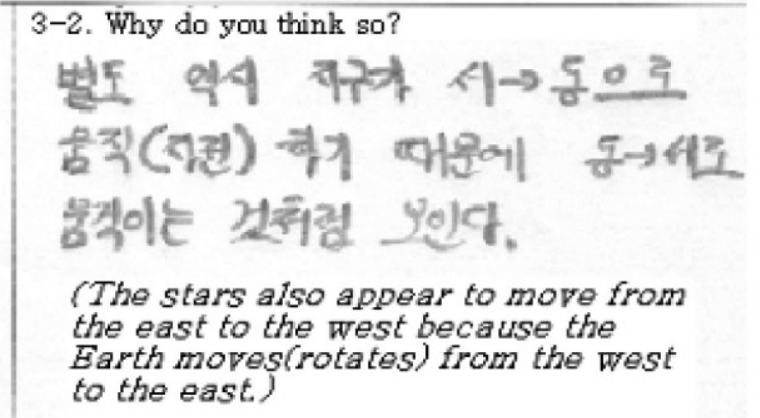

Figure 9. Student J's description of the stars' daily motion in the questionnaire. 
suggestion less logical and less scientific during the interview time. Student I showed the following description (Figure 10) and explanation.

Researcher: What is the stars' apparent daily motion?

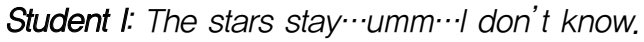
Researcher: (seeing the student l's drawing in the questionnaire) Do the stars move from the east to the west? Do you know about it well?

Student I: I think that the stars rise in the east and set in the west.

Researcher: (seeing the student l's description in the questionnaire) Why? Because the Earth rotates?

\section{Student l: Yes.}

When analyzing this student's questionnaire

3-1. Draw how the stars move at night.

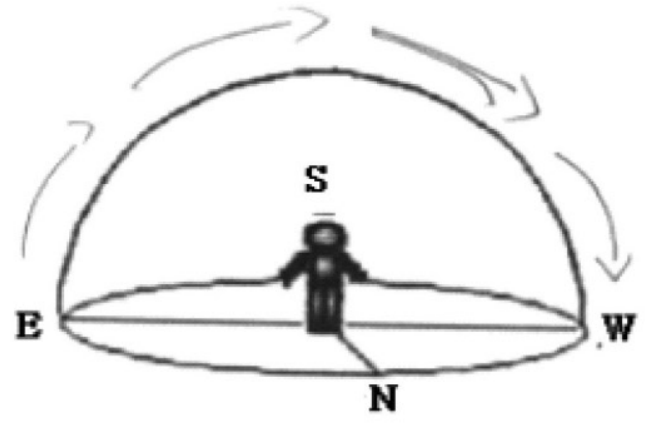

only, it seemed that the student understood exactly the daily apparent motion of the stars. However, during the interview, the student did not know that apparent motion exactly and responded that it is because of the Earth's rotation without a scientific explanation.

Two students gave descriptions that the stars appear to rise in the west and set in the east and could not explain it in detail during the interview (18\%). This included student A. The student A's illustration (Figure 11) and interview are below.

Researcher: Which way do the stars appear to move?

Student A: The stars appear to move from the east to the west. No. from the west to the east.

Researcher: Why do they appear to move that way?

Student A: It's because the Earth rotates from

3-2. Why do you think so?

(It is because the Earth rotates.)

Figure 10. Student I's description of the stars' daily motion in the questionnaire.

3-1. Draw how the stars move at night.

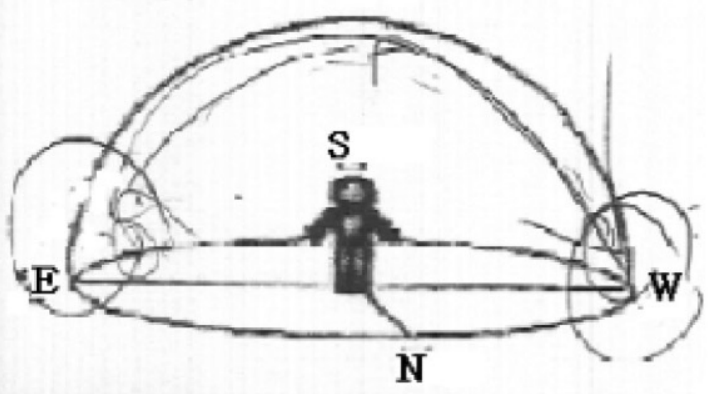

3-2. Why do you think so?

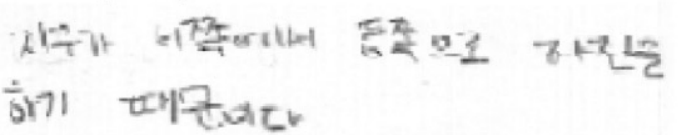

(It is because the Earth rotates from the west to the east.)

Figure 11. Student A's description of the stars' daily motion in the questionnaire. 
the west to the east.

Researcher: Then, your explanation for the stars is opposite to that of the Sun, isn't it?

Student A: What?

Researcher: (reminding of student 1's explanation for the Sun's apparent motion, which moves from the west to the east) You described that the Sun and the stars' apparent motion are the opposite way from each other. Right?

Student A: Yes.

Researcher: What happened to this?

Student A: I'll change my word to this way that the stars appear to rise in the east and set in the west.

This student was uncertain about the direction of how the stars appear to move. As soon as the researcher pointed out that the student's different opinions of the Sun's and the stars' apparent motion, the student changed the opinion for the stars' motion. Through analyzing student A's interview and questionnaire, it was shown that the student had no specific knowledge system about the stars' motion.

Two students of all gifted students used the Earth's revolution to explain the stars' motion. They answered the question of the stars' daily apparent motion as seen below.

Student C: (explaining the stars' motion with using a globe and a bulb)As the stars here move their place, we could see other stars which replace them because the Earth revolves around the Sun.

Student $K$ : We can see the stars' motion because we revolve around the Sun and the stars don't move. As the Earth revolves around the Sun and rotates itself, we can see that constellations change every season and the place of them changes, too. So the stars appear to move.

Student C used the Earth's revolution to explain the annual motion of the stars. On the other hand, student K used both the Earth's rotation and revolution to explain the seasonal change of constellations. These students seem not to understand clearly the question to ask the daily apparent motion of the stars during the interview.

Other than these students, there was a gifted student who does not have any concept of the stars at all. Student $\mathrm{H}$ did not describe anything in the questionnaire and answered "I don' $t$ know." to every question of the stars.

As a result of the research of the stars' motion, the majority of the gifted students (73\%) did not make a logical connection between the apparent motion of the stars and the Earth's rotation. A few students (18\%) explained the stars' annual motion instead of the stars' daily motion. This revealed that the knowledge learned in school was not integrated well in the student's cognitive system and the gifted students don't know well about the motion of the stars.

\section{Conclusion and Suggestion}

This study researched how gifted students recognize daily celestial motion and whether they can explain it scientifically or not. This study shows how the gifted students' knowledge about daily celestial motion was formed.

First, most gifted students were able to move frames of references. They knew that daily celestial motion is seen from the perspective of the observer on the Earth. And they were capable of shifting from their own Earth-based perspectives to heliocentric perspectives for explaining the motion. Therefore many students explained that celestial objects appear to move because of the other factors such as the Earth's rotation. This means that students recognize both heliocentric and the Earth-based frames of reference in learning the celestial daily motion.

Second, gifted students left much to be desired in understanding the moon' s and the stars' daily 
motion compared to the Sun's motion. More than half of the students who described that the Sun seems to move from the east to the west because of the Earth's rotation could not explain the moon's and the stars' daily motion as well as they did the Sun's motion. This indicates that gifted students did not have a coherent knowledge system about all celestial daily motions.

Third, a considerable number of gifted students could not back up their claim with a light bulb and a hand-held globe when they explain celestial daily motion. Some of them showed an aspect confusing the direction in turning the globe. They mentioned that the Earth rotates from the west to the east but they could not tell where the east and the west are when operating the globe. Other gifted students did not know where they are located in the globe and there are some cases of giving up explaining it with the globe. Like these, gifted students had trouble to explain what they said and they could not give on their opinion consistently. And as seen in the analyzed result, the reason of why gifted students could not explain the apparent motions of celestial objects is because of the lack of accurate understanding of the Earth's rotation. And this indicates that gifted students don't have scientific knowledge about how the celestial objects appear to move.

It is hard to generalize this study's result to every gifted students because the number of application subjects are small. But this result shows that gifted students don't have perfect knowledge system in understanding celestial motions. The basic ability to move frames of reference and knowledge to understand the daily apparent motion of celestial objects are necessary for learning other astronomic topics. Therefore, certain teaching strategy is needed to help gifted students to have a more sophisticated understanding of those motions (Plummer et al., 2011).

With reflecting this result, this study suggests more studies as follows for the formation of elementary students' scientific knowledge system about the Earth's rotation and daily celestial motions.

First, it will be good to develop a specific teaching method and strategy to teach the celestial motions for gifted students. It needs to collect information of teaching method and strategy conducted in the elementary school and to research a more effective teaching strategy to improve the original one. Also researchers have to study how much it affects to gifted students. This will be an applicable guideline in the field.

Second, a future research which compares gifted students' knowledge system with general students' system in same condition will lead to more generalized conclusion. And it will be possible to analyze in-depth results of difference how gifted students and general students form a knowledge system.

Third, a research is required to study how important acquiring a consistent and scientific knowledge of celestial motions caused by the Earth's rotation is. It needs to clear that knowledge of the Earth's rotation and the celestial daily motions is based on an ability to move frames of references and to study in which students who can move frames of reference and students who cannot move them show difference.

\section{REFERENCE}

American Association for the Advancement of Science). (2001). Atlas of Scientific Literacy: Volume I. Washington, DC: Author.

Byun, J. S., Jung, J. G., Moon, B. C., \& Jeong, J. W. (2004). High School Student Conceptions on the Motion of the Earth and Moon. Journal of the Korean Earth Science Society, 25(7), 519-531.

Chae, D. H. (2004). The changes of preservice and inservice elementary school teachers' concepts of the solar system based upon their exposure to the earth motion centric solar system model. Journal of the Korean Association 
for Research in Science Education, 24(5), 886901.

Cho, K. S., Chung, D. H., Kim, B. H., Park, K. S., \& Park, K. J. (2011). The effects of astronomical animation module on earth science gifted students's conceptual change of diurnal motion. Journal of the Korean Earth Science Society, 32(2), 200-211.

Jung, N. S., Woo, J. O., \& Jeong, J. W. (1995). Analysis of frameworks on astronomic conceptions in secondary school students. Journal of the Korean Earth Science Society, 16(3), 188-193.

Kavanagh, C., Agan, L., \& Sneider, C. (2005). Learning about phases of the moon and eclipses: A guide for teachers and curriculum developers. Astronomy Education Review, 4(1), 34.

Lee, Y. S., Kim, S. S., Lee, S. G., Nam, Y. R., Joo, E. J., \& Lee, H. L. (2011). The per-service elementary school teachers' conceptual understanding survey about astronomical field. The Korean Society of Earth Science Education, 4(3), 297-304.

Na, J. J., Park, J. B., \& Kook, D. S. (2010) The effects of science instructions applying 3D planetarium software: Using the unit 'Earth and Star' for the 8th grade. Journal of the Korean Earth Science Society, 31(2), 164-171

National Research Council. (1996). National Science Education Standards. Washington, DC: National Academy Press.

Nussbaum, J. (1986). Students' perception of astronomical concepts. In J. J. Hunt (Ed.), Proceedings of the GIREP Conference 1986. COSMOS An Educational Challenge (pp. 87-97). Copenhagen, Denmark: ESA Publications Division.

Plummer, J. D. (2009). Early elementary students' development of astronomy concepts in the planetarium. Journal of research in science teaching, 46(2), 192-209.

Plummer, J. D., Wasko, K. D., \& Slagle, C. (2011). Children Learning to Explain Daily Celestial Motion: Understanding astronomy across moving frames of reference. International
Journal of Science Education, 33(14), 1963-1992.

Sharp, J. G. (1996). Children's astronomical beliefs: A preliminary study of Year 6 children in south-west England. International Journal of Science Education, 18(6), 685-712.

Shen, J., \& Confrey, J. (2010). Justifying alternative models in learning astronomy: A study of $\mathrm{K}-8$ teachers' understanding of frames of reference. International Journal of Science Education, 32(1), 1-29.

Shim, K. C., Kim, H. S., \& Chung, J. I. (2004). Conceptual changes of middle school students on the motion of the moon using the cognitive conflict instructional model. Journal of Korea Earth Science Society, 25(5), 348-363.

Subramaniam, K., \& Padalkar, S. (2009). Visualisation and reasoning in explaining the phases of the moon. International Journal of Science Education, 31(3), 359-417.

The Ministry of Education and Human Resources Development (2007). 2007 revised science curriculum. The Ministry of Education and Human Resources Development.

Trumper, R. (2006). Teaching future teachers basic astronomy concepts - seasonal change- at a time of reform in science. Journal of Research in Science Teaching, 43(9), 879-906.

Trundle, K. C., Atwood, R. K., \& Christopher, J. E. (2002). Preservice elementary teachers' conceptions of moon phases before and after instruction. Journal of Research in Science Teaching, 39(7), 633-658.

Trundle, K. C., Atwood, R.K., \& Christopher, J. E. (2007). Fourth-grade elementary students' conceptions of standards-based lunar concepts. International Journal of Science Education, 29(5), 595-616. 